\title{
Novel pyrrolocoumarin derivatives
}

\author{
Valery F. Traven, Vasiliy V. Suslov, and Evgeny N. Gordeev \\ Department of Organic Chemistry, D. Mendeleev University of Chemical Technology of Russia, \\ 125047 Moscow, Russia \\ E-mail: traven@main-gw.muctr.edu.ru
}

(received 20 May 00; accepted 21 Sep 00; published on the web 29 Sep 00)

\begin{abstract}
Ethyl esters of 2-[(4`,7`-dimethyl-2 'oxo-2'H-1'-benzopyran-6 'yl)azo]-2-alkyl-3-oxobutanoic acids have been synthesized from diazotized 6-amino-4,7-dimethyl-2H-1-benzopyran-2-one.and ethyl esters of 2-alkyl-3-oxobutanoic acids in the presence of sodium acetate. The esters have then been transformed into indoles (obviously via intermediate hydrazones) by the Fischer reaction in the presence of acids. This is a way to novel class of indole derivatives -ethyl esters of 3,7-dihydro-7-oxopyrano[3,2-e]indol-2-carboxylic acids with different substituents. All the new compounds have been characterised by ${ }^{1} \mathrm{H}-\mathrm{NMR}$ and mass spectra, and elemental analyses.
\end{abstract} Keywords: Pyrrolocoumarins, diazotization Fisher indole synthesis

\section{Introduction}

2H-1-benzopyran-2-one (coumarin) derivatives belong to one of the most widespread classes of natural compounds (1). Some of them, for example, furocoumarin derivatives - psoralens and angelicins have been used as medicines (2). Pyrrolocoumarins showed also photobiological activity and antiproliferative effect (3).

Some of the pyrrolocoumarins have previously been synthesized by the reaction between aminocoumarins and benzoin (4). Cyclization of the corresponding hydrazones by the Fischer 
reaction has also been used $(3,5)$. However, these procedures have only been applied for synthesis of alkyl-and aryl-substituted pyrrolocoumarins.

In this article we report a new way to ethoxycarbonyl substituted derivatives of pyrrolocoumarins. This procedure is based on the Japp-Klingemann synthesis of hydrazones (6, 7) and provides a convenient way to pyrrolocoumarins with carboethoxy function in pyrrole ring. A number of derivatives of 3,7-dihydro-4,9-dimethyl-7-oxopyrano[3,2-e]indol-2-carboxylic acid ethyl esters has been synthesized.

\section{Results and Discussion}

4,7-Dimethyl-6-aminocoumarin $\underline{\mathbf{1}}$ has been prepared by reduction of 4,7-dimethyl-6nitrocoumarin (8) with powder of cast iron in a mixture of dioxan-water and $\mathrm{pH}=4-5$. This procedure is more convenient and provides a better yield of $\mathbf{1}$ than the syntheses reported previously (4).

Aminocoumarin 1 has been diazotized by a standard procedure. The formed diazocompound has then been coupled with $\alpha$-substituted acetoacetic esters in the presence of sodium acetate (scheme 1).<smiles>Cc1cc2oc(=O)cc(C)c2cc1N</smiles><smiles>Cc1cc2oc(=O)cc(C)c2cc1N=[N+]</smiles>

$\mathrm{R}=\mathrm{H}, \mathrm{Me}, \mathrm{Ph}$

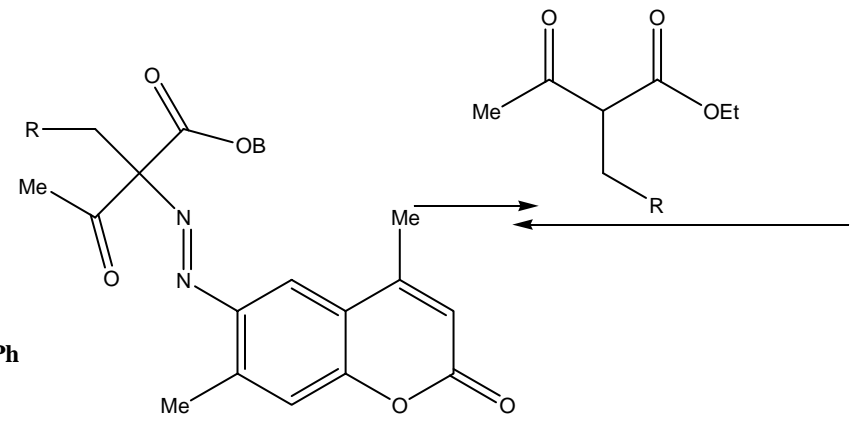

Scheme 1 
Compounds 2a,b have been isolated and purified as solid products. However, product 2 has been isolated as an oil and transformed then without purification into solid hydrazone 3 by hydrochloric acid treatment at room temperature (scheme 2).

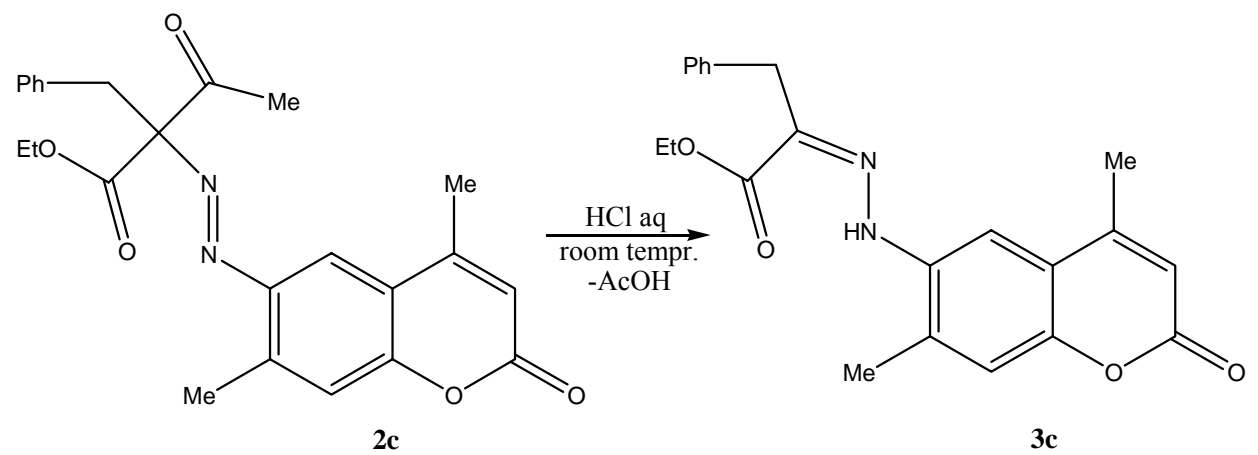

\section{Scheme 2}

Solvent, catalyst and temperature of reaction are of a great importance for indole derivatives synthesis of by the Fischer reaction $(7,9)$.

Heating of hydrazone $3 \mathbf{c}$ at $80{ }^{\circ} \mathrm{C}$ in $\mathrm{HCl}$-ethanol gave pyrrolocoumarin $4 \mathbf{c}$. The ester $\mathbf{2 b}$ has smoothly been transformed to pyrrolocoumarin $\mathbf{4 b}$ in the same conditions without isolation of the intermediate hydrazone. The ester $\mathbf{2 a}$ has also been transfomed directly to pyrrolocoumarin 4a, but solution of p-toluenesulphonic acid monohydrate in glacial acetic acid was used as a cyclization reagent (scheme 3).

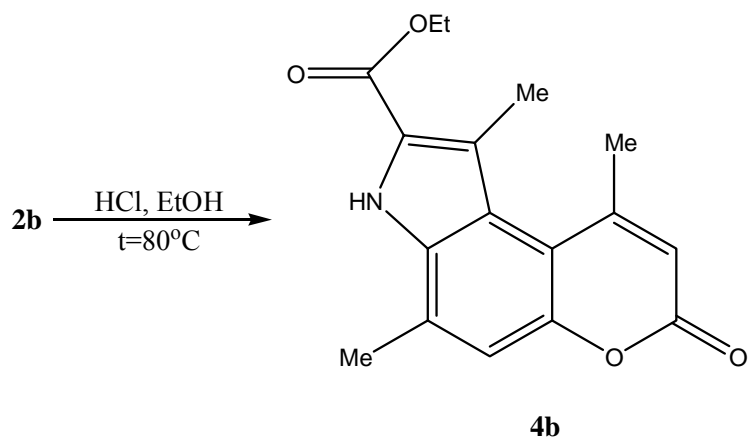

\section{Scheme 3}



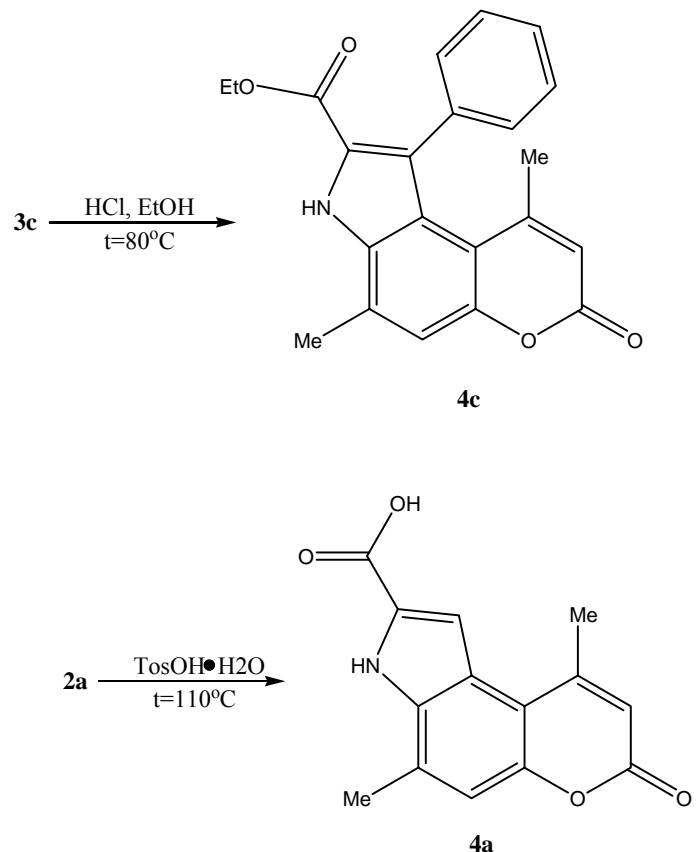

\section{${ }^{1}$ H-NMR spectra}

All ${ }^{1} \mathrm{H}-\mathrm{NMR}$ spectra were taken on a Bruker WR-200SV spectrometer at $200 \mathrm{Mhz}$ in CDCl3 solution using tetramethylsilane as internal standard. Chemical shifts are given in ppm.

The chemical shifts for the protons of Me-group at C-4 of compounds 2a-tc appeared at 2.40-2.44 ppm. The chemical shifts for the protons of Me-group at C-9 of compounds 4a-b were found at $2.69 \mathrm{ppm}$ for $\mathbf{4 a}$ and at $2.75 \mathrm{ppm}$ for $\mathbf{4 b}$. In the case of $\mathbf{4 c}$, however, the chemical shifts for the protons of Me-group at C-9 was found at a relatively higher field at $1.00 \mathrm{ppm}$. This shift towards a higher field could be caused by an anisotropic shielding effect of phenyl group located at $\mathrm{C}-1$ of $\mathbf{4 c}$. 


\section{Mass spectra}

All mass spectra were scanned on a SSQ-710 (Finnigan MAT) spectrometer at the energy of ionising electrons equal to $70 \mathrm{ev}$.

Molecular ions of compounds 3c and 4a-(c have high intensity peaks (near 75-85 \%). Azo compounds 2a and $\mathbf{2 b}$ have not molecular ions peaks. Their molecular ions decompose under electron impact in several directions (scheme 4).<smiles></smiles>

\section{Scheme 4}

The decomposition of molecular ions of compounds $4 \mathbf{a}^{-\mathbf{k}} \mathbf{c}$ goes either with loss of $\mathrm{CH} 3 \mathrm{CO}$, then $\mathrm{CO}$ or with loss of COOEt. 


\section{Experimental Section}

\section{6-Amino-4,7-dimethyl-2H-1-benzopyran-2-one (6-amino-4,7-dimethylcoumarin) 1.}

A mixture of $35 \mathrm{~g}$ powder of cast iron, $100 \mathrm{~mL}$. of water and $10 \mathrm{~mL}$. of glacial acetic acid was refluxed for 15 minutes. A boiling solution of 6-nitro-4,7-dimetylcoumarin (42 g.0.2 mole) in $500 \mathrm{~mL}$. of 1,4-dioxan was then added into the mixture. It has then been refluxed for $7 \mathrm{~h}$. The resulting reaction mixture was neutralized with $46 \mathrm{~g}$. solid of sodium carbonate and filtered from a solid precipitate. The precipitate was washed with boiling 1,4-dioxan. The filtrate was then poured into $300 \mathrm{~mL}$. of cold water. A solid was filtered off, washed with water, dried and recrystallized from 1,4-dioxan. Yield 31.0 g. ( 82\%), mp=203-205 (lit. (4) 203-205 (1,4dioxan)).

\section{Synthesis of Azo Compounds 2a-(c (General Procedure)}

A solution of 6-amino-4,7-dimetylcoumarin 1 (9.45 g. 0.05 mole) in a mixture of $25 \mathrm{~mL}$ of hydrochloric acid and $50 \mathrm{~mL}$ of glacial acetic acid was diazotized at $0{ }^{\circ} \mathrm{C}$ with sodium nitrite solution (4 g. (0.055 mole) dissolved in $10 \mathrm{~mL}$. of water). After keeping at this temperature for 3 $\mathrm{h}$ the resulting solution of diazonium salt was filtered and added into mixture of $75 \mathrm{~mL}$ of glacial acetic acid, 0.051 mole of 2-alkyl-3-oxobutanoic acid ethyl ester and $50 \mathrm{~g}$. (0.37 mole) of sodium acetate $(\mathrm{AcONa} 3 \mathrm{H} 2 \mathrm{O})$ at 0 to $5{ }^{\circ} \mathrm{C}$ and $\mathrm{pH}=5.5$. The mixture was left for $10 \mathrm{~h}$. After that an equal volume of water was added into the mixture. The crude product was collected, washed with ethanol, then water and recrystallized from ethanol (treatment of compound 2c see below).

2-[(4',7'-Dimethyl-2'-oxo-2'H-1'-benzopyran-6'-yl)azo]-2-methyl-3-oxobutanoic acid ethyl ester 2a.

Yield 15.0 g. $(\sim 87 \%), \mathrm{mp}=84-85{ }^{\circ} \mathrm{C}{ }^{1} \mathrm{H}-\mathrm{NMR}(\mathrm{CDCl} 3, \mathrm{~J} / \mathrm{Hz}) \delta 1.29$ (t, 3H, Me, JMe,-CH2-=7.5, COOEt); 1.71 (s, 3H, 2-Me); 2.34 (s, 3H, $\left.7^{`}-\mathrm{Me}\right) ; 2.44$ (d, 3H, $\left.4^{`}-\mathrm{Me}, \mathrm{J} 4^{`}-\mathrm{Me}, 3^{`}=1.6\right) ; 2.64$ (s, 3H, MeCO); 4.29 (q, 2H, J-CH2-,Me=7.5, COOEt); 6.28 (d, 1H, 3`-H, J3`,4`-Me=1.6); 7.25 (s, 1H, $\left.8^{\prime}-\mathrm{H}\right) ; 7.64$ (s, 1H, $\left.5^{`}-\mathrm{H}\right) . \mathrm{MS}: \mathrm{m} / \mathrm{z}(\%): 302\left(\mathrm{M}^{+}-\mathrm{CH} 2=\mathrm{C}=\mathrm{O}, 9\right), 271\left(\mathrm{M}^{+}\right.$-COOEt, 25), 201 $\left(\right.$ Coum-N=N $\left.\mathrm{N}^{+}, 65\right), 173\left(\mathrm{Coum}^{+}, 100\right)$. Anal. calcd. for C18H20N2O5: C 62.78; H 5.85; N 8.13. Found C 63.00; H 5.81; N 8.15. 
2-[(4 ,7`-Dimethyl-2`-oxo-2’H-1`-benzopyran-6`-yl)azo]-2-ethyl-3-oxobutanoic acid ethyl ester $2 \mathbf{b}$.

Yield 15.4 g. $(\sim 86 \%), \mathrm{mp}=88-90{ }^{\circ} \mathrm{C} .{ }^{1} \mathrm{H}-\mathrm{NMR}(\mathrm{CDCl} 3, \mathrm{~J} / \mathrm{Hz}) \delta 1.04$ (t, 3H, Me, JMe,-CH2=7.5, 2-Et); 1.29 (t, 3H, Me, JMe,-CH2-=7.5, COOEt); 2.29 (q, 2H, J-CH2-,Me =7.5, 2-Et); 2.31 (s, 3H, 7`-Me); 2,44 (d, 3H, $4^{`}-\mathrm{Me}, \mathrm{J}^{`}$ '-Me,3`=1.8); 2.64 (s, 3H, MeCO); 4.29 (q, 2H, -CH2-, J$\mathrm{CH} 2-, \mathrm{Me}=7.5, \mathrm{COOEt}) ; 6.28$ (d, 1H, $\left.3^{`}-\mathrm{H}, \mathrm{J} 3{ }^{`}, 4^{`}-\mathrm{Me}=1.8\right) ; 7.26$ (s, 1H, 8`-H); 7.63 (s, 1H, $5^{`}{ }^{`}$ H). MS: m/z(\%): $330\left(\mathrm{M}^{+}-\mathrm{CH} 2=\mathrm{CH} 2,7\right), 316\left(\mathrm{M}^{+}-\mathrm{CH} 2=\mathrm{C}=\mathrm{O}, 6\right), 288\left(\mathrm{M}^{+}-\mathrm{CH} 2=\mathrm{CH} 2\right.$ $\mathrm{CH} 2=\mathrm{C}=\mathrm{O}, 12), 285\left(\mathrm{M}^{+}\right.$-COOEt, 5), $201\left(\right.$ Coum-N=N $\left.{ }^{+}, 76\right), 173\left(\mathrm{Coum}^{+}, 100\right)$. Anal. calcd. for C19H22N2O5: C 63.68; H 6.19; N 7.82. Found: C 63.83; H 6.31; N 7.80.

a-[(E)-2-(4 ,7`-Dimethyl-2`-oxo-2H-1`-benzopyran-6`yl)hydrazono]-benzenepropanoic acid ethyl ester 3c.

Azo compound 2c as an oil was treated with cold diluted hydrochloric acid and product was obtained as crystals. The hydrazone 3c was filtered off, washed with ethanol, then water. The product 3c was recrystallized from ethanol. Yield 13g. $(\sim 70 \%), \mathrm{mp}=160-162{ }^{\circ} \mathrm{C}$. ${ }^{1} \mathrm{H}-\mathrm{NMR}$ $(\mathrm{CDCl} 3, \mathrm{~J} / \mathrm{Hz}) \delta 1,29$ (t, 3H, Me, JMe,-CH2-=7.3, COOEt); 2.35 (d, 3H, 7`-Me, J7`-Me, $8^{`}=0.3$ ); 2.40 (d, 3H, 4`-Me, J4`-Me,3`=1.8); 3.89 (s, 2H, -CH2-Ph); 4.27 (q, 2H, -CH2-, J-CH2-,Me=7.3,

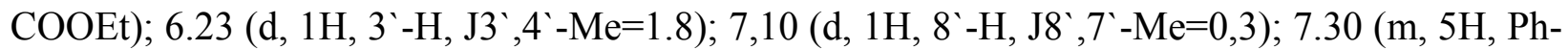
); 7.59 (s, 1H, 5 '-H); 12.24 (s,1H, NH). MS: m/z(\%): $378\left(\mathrm{M}^{+}, 75\right), 188\left(\mathrm{Coum}_{-} \mathrm{N}^{+}, 100\right), 173$ $\left(\mathrm{Coum}^{+}, 16\right)$. Anal. calcd. for C22H22N2O4: C 69.83; H 5.86; N 7.40. Found: C 69.62; H 5.92; N 7.34.

\section{3,7-Dihydro-4,9-dimethyl-7-oxopyrano[3,2-e]indole-2-carboxylic acid ethyl ester 4a.}

A mixture of azo compound 2a $1 \mathrm{~g}(0.0035 \mathrm{~mole}), 10 \mathrm{~mL}$ of glacial acetic acid and $1 \mathrm{~g}(0.0052$ mole) of TosOH$\cdot \mathrm{H} 2 \mathrm{O}$ has been refluxed for $12 \mathrm{~h}$. After cooling the reaction mixture was poured into $100 \mathrm{~g}$. of crushed ice. The product was filtered off, washed with water and recrystallized from 1,4-dioxan (activated charcoal). Yield $0.3 \mathrm{~g} .(\sim 36 \%), \mathrm{mp}>300^{\circ} \mathrm{C} .{ }^{1} \mathrm{H}-\mathrm{NMR}(\mathrm{CDCl} 3, \mathrm{~J} / \mathrm{Hz})$ $\delta 1.45$ (t, 3H, Me, JMe,-CH2-=7.5, COOEt); 2.61 (d, 3H, 4-Me, J4-Me,5 =1.0); 2.75 (d, 3H, 9Me, J9-Me,8=1.3); 4.46 (q, 2H, -CH2-, J-CH2-,Me= 7.5, COOEt); 6.28 (d,1H, 8-H, J8,9$\mathrm{Me}=1.3) ; 7.17$ (d,1H, 5-H, J5,4-Me=1.0); 7.56 (d, 1H, 1-H, J1H,NH = 2.14); 9.08 (c,1H, NH). MS: m/z(\%): $285\left(\mathrm{M}^{+}, 81\right), 257\left(\mathrm{M}^{+}-\mathrm{CH} 2=\mathrm{CH} 2,11\right), 240\left(\mathrm{M}^{+}-\mathrm{Et}-\mathrm{O}, 14\right), 212\left(\mathrm{M}^{+}\right.$-COOEt, 19). Anal. calcd. for C16H15NO4: C 67.36; H 5.30; N 4.91. Found: C 67.29; H 5.25; N 4.89. 


\section{3,7-Dihydro-1,4,9-trimethyl-7-oxopyrano[3,2-e]indole-2-carboxylic acid ethyl ester $\underline{4 b}$.}

Azo compound $\mathbf{2 b}(12.4 \mathrm{~g}, 0.035 \mathrm{~mol})$ was added into a mixture of $30 \mathrm{~mL}$ ethanol and $15 \mathrm{~mL}$ SOC12. After refluxing for $12 \mathrm{~h}$ the reaction mixture was cooled. The precipitate was filtered off, washed with ethanol, then water and recrystallized from ethanol. Yield $8.8 \mathrm{~g}$. ( 85.0\%), $\mathrm{mp}=178-180{ }^{\circ} \mathrm{C} .{ }^{1} \mathrm{H}-\mathrm{NMR}(\mathrm{CDCl} 3, \mathrm{~J} / \mathrm{Hz}) \delta 1.45$ (t, 3H, Me, JMe,-CH2-=7.5, COOEt); 2.57 (d, 3H, 4-Me, J4-Me,5 =0.8); 2.69 (d, 3H, 9-Me, J9-Me,8=1.1); 2.78 (s, 3H, 1-Me); 4.46 (q, 2H, CH2-, J-CH2-,Me =7.5, COOEt); 6.25 (d, 1H, 8-H, J8,9-Me=1.1); 7.12 (d, 1H, 5-H, J5,4$\mathrm{Me}=0.8) ; 9.0(\mathrm{~s}, 1 \mathrm{H}, \mathrm{NH}) . \mathrm{MS}: \mathrm{m} / \mathrm{z}(\%): 299\left(\mathrm{M}^{+}, 80\right), 254\left(\mathrm{M}^{+}\right.$- Et-O, 67), 226(M ${ }^{+}$- COOEt, 21). Anal. calcd. for C17H17NO4: C 68.22; H 5.72; N 4.68. Found: C 67.98; H 5.68; N 4.73.

3,7-dihydro-4,9-dimethyl-7-oxo-1-phenylpyrano[3,2-e]indole-2-carboxylic acid ethyl ester 4c.

Hydrazone 3c (10.5 g,0.028 mol) was added to a mixture of $40 \mathrm{~mL}$ ethanol and $15 \mathrm{~mL} \mathrm{SOCl} 2$. After refluxing for $12 \mathrm{~h}$ the reaction mixture was cooled. The precipitate was filtered off, washed with ethanol, then water. The compound $4 \mathrm{c}$ was recrystallized from ethanol. Yield 5 g. ( 49.7\%), $\mathrm{mp}=223-225{ }^{\circ} \mathrm{C} .{ }^{1} \mathrm{H}-\mathrm{NMR}(\mathrm{CDCl} 3, \mathrm{~J} / \mathrm{Hz}) \delta 1.10(\mathrm{t}, 3 \mathrm{H}, \mathrm{Me}, \mathrm{JMe},-\mathrm{CH} 2-=7.5, \mathrm{COOEt}) ; 1.56(\mathrm{~d}$, 3H, 9-Me, J9-Me,8 =1.0); 2.61 (d, 3H, 4-Me, J4-Me,5 =0.8); 4.20 (q, 2H, -CH2-, J-CH2-,Me $=7.5$, COOEt); 6,02 (d, 1H, 8-H, J8,9-Me=1.0); 7,20 (d, 1H, 5-H, J5,4-Me=0.8); $7.37(\mathrm{~m}, 5 \mathrm{H}$, $\mathrm{Ph}) ; 9.28$ (s,1H, NH). MS: m/z(\%): $361\left(\mathrm{M}^{+}, 85\right), 316\left(\mathrm{M}^{+}\right.$- Et-O, 27), 288( $\mathrm{M}^{+}$- COOEt, 4). Anal. calcd. for C22H19NO4: C 73.12; H 5.30; N 3.88. Found: C 73.11; H 5.28; N 3.77.

\section{References}

1. Dean F.M. Naturally Occurring Oxygen Ring Compounds, Butterworth: London, 1963.

2. Dall'Acqua F.; Vedaldi D.; Caffieri S.; Guiotto A.; Rodighiero P.; Baccichetti F.; Carlassare F.; Bordin F. J. Med. Chem. 1981, 24, 178.

3. Guiotto A.; Chilin A.; Manzini P.; Dall'Acqua F.; Bordin F.; Rodighiero P.Farmaco 1995, 50,479 .

4. Meyer H. Acta Chem. Scand., Ser. B, 1975, 29, 133. 
5. Khan M.; Morley B. J. Heterocyclic Chem. 1979, 16, 997.

6. Japp F.R.; Klingemann F.; Ber., 1887, 20, 2942, 3284, 3398.

7. SundbergR.J.; Indoles, Academic Press, 1996.

8. Clayton A. J. Chem. Soc. 1910, 97, 1398.

9. Robinson R. The Fischer Indole Synthesis, Wiley, Chichester, 1982. 